\title{
A Computer Hardware/Software/Services Planning and Selection Course for the CIS/IT Curriculum
}

\author{
John Maniotes and Charles R. Winer \\ Purdue University Calumet, Hammond, IN, USA
}

maniotes@calumet.purdue.edu winer@calumet.purdue.edu

\begin{abstract}
A problem that has been neglected in CIS/IT curricula is, how will students and recent graduates go about planning and selecting computer hardware, software, and services in a cost effective manner. The authors will present a list of compelling arguments for the establishment of such a course and describe its contents and the details of its implementation.
\end{abstract}

Keywords: CIS/IT Curriculum, RFP's, Computer Performance, Selection Approaches, Procurement Strategies, Negotiation Techniques, Contract Clauses, Conversion Issues.

\section{Introduction}

The purpose of this paper is to present the case that viable Computer Information Systems (CIS) and Information Technology (IT) academic programs should include a senior level course in the area of computer hardware, software, services planning and selection. Over the past 40 years, a large body of knowledge has formed in this area, and the time has come for educators to seriously consider the inclusion of such a course in CIS and IT programs.

In many cases today, enterprise level hardware and software systems range in cost from hundreds of thousands to millions of dollars. Today's CIS/IT graduates need such a course in order to plan, design, and select computer hardware, software, and services in a cost effective manner in order to meet an organization's needs. Whether or not university graduates are directly in charge, or just as importantly, they are an active member of a committee that is responsible for the successful acquisition of hardware, software, and/or services, the content of a course such as this is becoming ever more important. The authors' engagement (consulting) activities with government, not-for-profit, and various size corporations continues to demonstrate that many of their current staff do not have the necessary background or expertise in subject matters identified in this paper to help protect their organizations from bad decisions.

During the past two decades, Purdue University Calumet has offered a senior level course titled, CIS483 Computer Hardware/Software Selection, which has been refined and revised over the years. Well over 1,000 students have taken this course during that time. Feedback from our CIS

alumni as well as business and indus-

Material published as part of this journal, either on-line or in print, is copyrighted by Informing Science. Permission to make digital or paper copy of part or all of these works for personal or classroom use is granted without fee provided that the copies are not made or distributed for profit or commercial advantage AND that copies 1) bear this notice in full and 2) give the full citation on the first page. It is permissible to abstract these works so long as credit is given. To copy in all other cases or to republish or to post on a server or to redistribute to lists requires specific permission from the publisher at Publisher@InformingScience.org try advisory committee members are a constant source of input in this revision process. Early versions of the course have been described by (Maniotes \& Winer 1999) and the various options in our CIS programs have been described by (Winer \& Maniotes 2001). 


\section{The Major Topics}

Topics for this upper level course should include the following:

(1) Survey of the computer and IT market places.

(2) Past, present, and future trends in IT

(3) Organizational and administrative considerations in the selection process

(4) Analysis of needs (requirements analysis)

(5) How to prepare and formulate requirements for RFx's (RFP's, RFB's, RFQ's and RFI's)

(6) The composition of the Request for Proposals (RFP) and the Request for Bids (RFB) documents

(7) Vendor responses to the RFP or RFB

(8) How to validate proposed system's characteristics and performance

(9) Performance measurement approaches including benchmarking of systems

(10) Application of various kinds of quantitative selection approaches

(11) How to conduct the negotiation process with vendors and identify techniques and maneuvers to use via role playing techniques

(12) Application of various procurement techniques, such as buy, rent, or lease and determine quantitatively the breakeven points for each technique

(13) How to analyze vendor contracts and their clauses

(14) Pertinent patents, copyrights, licensing agreements, and trade secrets in the IT industry

(15) Identification of expected conversion and compatibility issues

(16) Installation and implementation considerations

(17) Check lists of useful information

(18) The student team project

(19) Case studies

A fundamental task for CIS/IT educators is to help students understand the importance, composition, and legal issues involved with many of these major topics. Furthermore, these topics can serve as a guide to CIS/IT educators to consider in customizing a course such as this.

\section{The Instructional Materials}

A single textbook covering in detail all of the aforementioned topics does not currently exist under one cover. However, books exist on some of these individual topics such as topics 5, 9, 11, 12, and 13 and are on reserve for student access via our University's reference library. Some of the classic papers on computer selection (Timmreck, 1973) and performance evaluation (Lucas, 1971) can serve as a guide for the instructor teaching this course for the first time. The authors have also compiled an Omnibus of useful articles, lecture outlines, class notes, problems, and exercises (Maniotes, Winer, \& Maniotes 2003) for students to use in the course. 
We have opted to make available on the Web and place on reserve in the University's library, articles, papers, and RFP's, dealing with the identified topics. Many of these materials are also available on the course's Web site, http://bb.calumet.purdue.edu, accessible by all enrolled students of the class. Also, whenever possible, we have given the students, the URL's of these publications, so they may access the articles via the Web. The articles and papers are from over 25 magazines, newspapers, and other publications such as: Auerbach Publishers, CIO Magazine, Communications of the ACM, ComputerWorld, Datamation, DataPro Reports (Gartner), Fortune, InfoWorld, Interactive Week, PC Magazine, Red Herring Magazine, Software Magazine, Upside Magazine, and the Wall Street Journal.

Various companies, businesses, local government agencies, school districts, and organizations have contributed sample RFP's, RFB's, Request for Information (RFI's), and Request for Quotations (RFQ's) that are also placed on reserve in the University's library for students to examine.

During the past 20 plus years, we have also served as consultants to a variety of industrial organizations, local governments, and school districts. We have applied many of the fundamentals covered in the aforementioned topics. As an integral part of these consultations, we have researched, designed, specified, evaluated, and implemented computer hardware, applications software, networks, and services. From these consulting experiences, we bring in a variety of real-world examples, not commonly found in textbooks.

\section{Description of the Topics}

Anyone who engages in the art of selection must know the current market place and the trends occurring in the IT field (Topics 1, and 2). Early in the semester, definitions of the computer and IT markets (vendors) are discussed. We have found that the annual market surveys published in The Wall Street Journal, Datamation, Software, Red Herring, and Upside magazines are very helpful and provide useful statistics on the composition of the market place as well as the market leaders.

From these survey results, each student is assigned a case study (Topic 19) on a different vendor in the IT field. The students give three short in-class updates on their progress in developing their written short report describing the vendor's main products or services, financial condition, R\&D effort, market strengths, their competition, etc. Furthermore, students are required to make recommendations on whether it is advisable to do business with the assigned vendor and why or why not.

The organizational and administrative considerations in the selection process (Topic 3 ) and requirements analysis (Topic 4) have usually been covered in great detail in other CIS courses. We simply conduct a review of these topics. We also review important feasibility tests and criteria used to determine when a manual application should be or not be automated.

Topics 5 and 6, the composition of the RFP and RFB, covers the format of a typical RFP and RFB, the classification of the system requirements as mandatory vs. desirable or as general vs. detail, the make-up of technical questionnaires, and the ground rules and proposal instructions for vendors to follow in replying to an RFP or RFB. Sample RFP's and RFB's in the library are used as examples for students to examine. Topic 6 has been described in detail by (Maniotes \& Winer 2003).

Topic 7, vendor's responses to the RFP's or RFB's is best handled by either placing sample vendor responses on reserve in the library or inviting a vendor in to discuss this topic from the vendor's perspective. Items dealing with a vendor's support, pricing strategies and discounts, shipping and installation considerations, contractual terms and conditions, as well as how sales representatives are remunerated, are particularly helpful to students. 
Topics 8 and 9, validation of the proposed system and performance approaches range from techniques used to validate system characteristics and system times (performance). For the latter, we stress the importance of live, standardized, and artificial benchmarks, simulation packages, and hardware and software monitors that can be used to predict and validate throughputs and response times.

Topic 10, selection techniques, we cover various ad-hoc approaches, the weights and scores approach, and the cost value technique. It is always helpful to have articles from the literature that actually give real world examples on how these techniques are applied in various corporate selection scenarios. Also how weights and scores are derived is of particular interest to students who have never used this technique.

Topic 11, vendor negotiations, we discuss the makeup of the negotiating team, the techniques a user can use during the negotiation process, and maneuvers that a vendor may be expected to use. This topic is best taught with actual examples and experiences. We have found this portion of the course to be especially successful when we have invited a lawyer to give his/her perspective on the art of negotiation with hardware and software vendors and developers.

Topic 12, procurement criteria and decision issues, deals with such situations as purchasing from a vendor or used equipment dealer, renting from a vendor, leasing from a third party, and leaseto-ownership/purchase variations. Various acquisition analysis for determining break even points are also illustrated. Inviting a chief financial officer or an accountant who has concluded large computer oriented procurements and financed them successfully is always of interest and benefit to the students.

Topic 13, vendor contracts, we discuss various types of clauses and contracts for purchase, rent, and lease of hardware, software, services, maintenance, training, etc. Inviting a lawyer who can discuss these clauses as well as the tactics used to enforce a contract, such as litigation or arbitration is also highly desirable.

Topic 14, patents, copyrights, licensing, and trade secrets, we discuss some of the major innovations and lawsuits that have occurred in the IT industry and the impact that they have had on the user community.

Topic 15, conversion and compatibility issues, we discuss the roles of emulators, simulators, sifters, and translators and identify vendors who specialize in data conversion services. With regard to compatibility issues, we not only identify issues related to software, but also with regard to acquiring new hardware that must still have compatible drivers for other existing components.

Topic 16, installation and implementation considerations, we describe the pros and cons of implementation techniques that have been used successfully such as parallel, piece meal, and plunge implementation methods.

Topic 17, check lists of useful information are distributed to students in the class prior to discussing each major topic. For example, when discussing topic 12, procurement, a check list of various cost issues related to hardware are discussed such as: leasing, rental, purchase, shipping, insurance, setup/installation, transportation, conversion, site preparation, supplies, etc. Lists of typical discounts and credits, include such items as training, multiple site licensing, and education/government discounts.

Topic 18, involves a student project. All students in the course participate in the project and work with three students per team, as indicated in the next section. 


\section{The Two Track Approach}

The CIS483 course has evolved into two tracks regarding the team project. If the enrollment in the course is heavily oriented toward systems analysis and database design majors, the instructor assigns the RFP Project which involves each team of three students to create their own "company." Each company is defined by the respective team to have specific assumptions that will guide its needs for specific hardware/software and/or IT services. The instructor then identifies additional specifics that all teams use in developing their specific RFP's for their own "company."

If the enrollment is heavily oriented toward applications programming and system networking majors, the instructor assigns the Benchmark Project, which also involves each team of three students each to determine the performance of a variety of different computer systems. Students play the role of a systems engineer and are involved in various performance issues, both hardware, and software related.

All students in the course participate on one of these projects each semester (Topic 18). Students are allowed to select their own team members, three per team. Each team then chooses their Project Leader. Furthermore, each team faces the following challenges for the project: research, both technical and legal, and documentation.

Those students participating on the Benchmark Project face the following additional tasks: analysis, design, programming, test data creation and key entry, testing, debugging, and implementation.

The student project stresses teamwork in addressing the defined problem and provides students with hands-on experience in developing an RFP or determining the performance of systems. Students quickly learn to communicate effectively with their team members in order for their project to succeed.

\section{The RFP Project}

One of the most challenging aspects of this course is teaching RFP concepts and fundamentals to senior students, many of whom have never seen or heard about an RFP before. Fortunately, we have placed on reserve in the University library sample copies of RFP's, RFB's, RFI's, and RFQ's which have been donated from many organizations. This enables students to peruse these documents at their leisure.

We have also placed on reserve textbooks, such as Haag Cummings, and Dawkins (1998) and Jessup and Valacich (2002), which describe the RFP process. We also encourage students to surf the Web, particularly in the government information technology marketplace, where RFP's are frequently posted. Federal and state agencies encourage vendors to download, review, and reply to their RFP's electronically, eliminating paperwork and streamlining their receipt of vendor proposals. Students will see that the composition of these RFP documents varies and there isn't a clear format/pattern that is followed.

A question often asked by many students is what are the important "main sections" of an RFP and what kind of information should the RFP contain. From our consulting experiences and past work with the University's computer center, we have developed an easy to use outline for the composition of the "ideal" RFP as described in Table 1. It consists of four sections and six appendices which are further described in (Maniotes \& Winer 2003). In short, the RFP is a document that clearly states a company's business problem and the technology infrastructure of the company. 


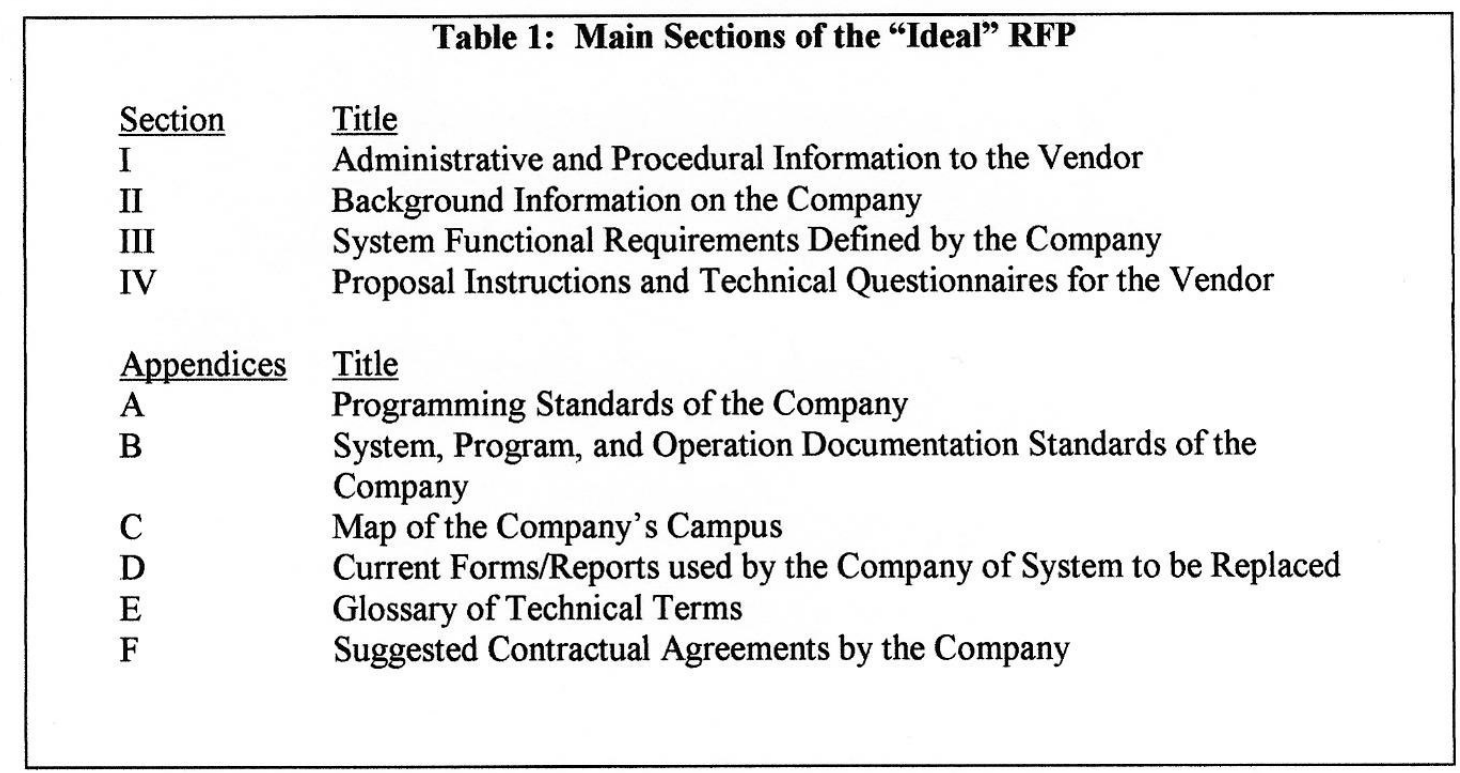

After the case study (Topic 19) is completed, each team of three students spends several (3) weeks defining their hypothetical company and developing assumptions on their company's needs for either computer hardware, networks, applications software, IT services, etc. In other words, they are performing a requirements analysis on their fictitious company. Based on that information, the students compose an RFP document, using the format described in Table 1 that explains in precise terms what their company needs are.

Students define their company's existing workflow, business processes (business model), and technology infrastructure. Students also create a detail blueprint of their company's technology infrastructure.

With the information contained in Table 1, we feel students will leave the course with a clear understanding of the composition of a good, functional RFP.

Over the past several years the following RFP projects have been dealt with:

1) A medium size company in need of payroll and financial application software including hardware considerations.

2) A municipal water billing system.

3) A high school district grading, scheduling, and attendance system and its corresponding financial applications.

4) A county law enforcement system.

5) A manufacturing company in need of a human resource system.

6) A payroll system for a small business.

7) Outsourcing services for a school system.

8) A network for a 10 member law firm.

9) An inventory control system for a plant and tree nursery

10) A Human Resource and Payroll system to replace the manually performed operations in a multi-plant manufacturing corporation 


\section{The Benchmark Project}

A benchmark is a set of computer programs which are designed to measure a multitude number of computer characteristics. For example, a benchmark can be used to evaluate the performance of a computer's CPU, I/O units, main and auxiliary storage units, and systems software such as the operating system, utilities, compilers, interpreters, etc.

Over the past few years the following benchmarks projects have been implemented using algorithms dealing with sorting, matrix operations (addition, subtraction, multiplication, and inversion), complex formulas and equations, statistical computations (mean, variance, and standard deviation), solutions to simultaneous linear equations, and the generation of fractals. Sometimes students are allowed to choose any compute-bound algorithm, subject to instructor approval, to measure the speed of various CPU's.

The Benchmark Project has been processed on a variety of systems at Purdue University Calumet, such as the: Intel x86 based PC's, Apple MAC PC's, Sun workstations, HP/DEC ALPHA and VAX minicomputers, and IBM mainframes. Programming languages used are $\mathrm{C}, \mathrm{C}++$, BASIC, Visual Basic, FORTRAN, and COBOL.

The Benchmark Project has been described in detail by (Maniotes, Winer, \& Maniotes 2000). Some of the high lights of the Benchmark Project are as follows:

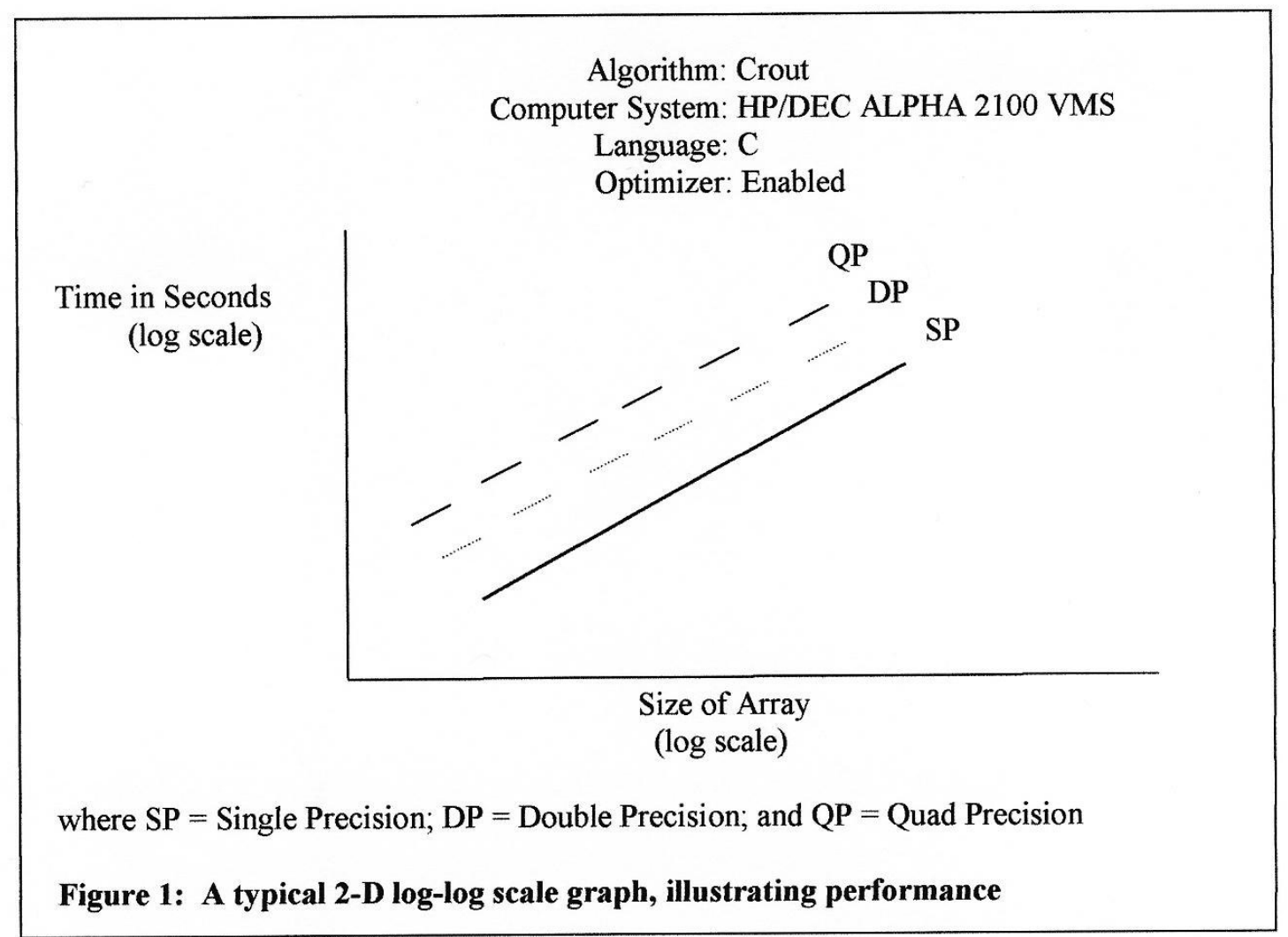

The outputs from the execution of a successful benchmark are the CPU time spent executing the assigned algorithm and the amount of main and disk storage utilized by the benchmark program. Also measured is the effect that the precision associated with the system, i.e. integer, single, double, and quad precision, has on the CPU time. Furthermore, whether the language optimizer is enabled or disabled, affects the CPU time. These results are summarized by students in the form of graphs and tables. For example, the benchmarks results dealing with an algorithm for the solu- 
tion of simultaneous linear equations are plotted on a 2-D log-log scale graph as shown in Figure 1:

Another useful table that students develop is the Average Relative Power (ARP), which is defined as:

$$
\mathrm{ARP}=\frac{\text { Processing time for system } \mathrm{x}}{\text { Processing time for system } \mathrm{y}}
$$

Table 2 shows a sketch of this table.

Table 2: The Average Relative Power (ARP) Table.

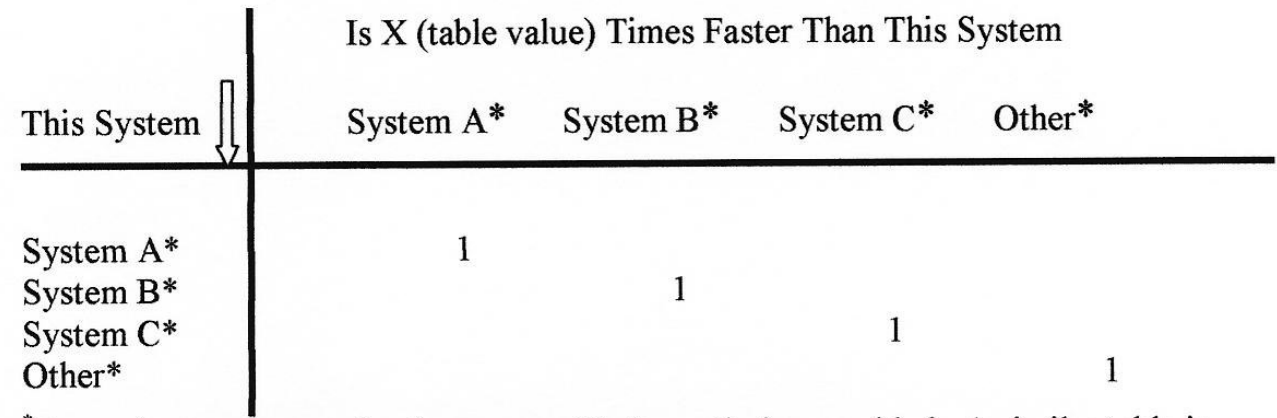

${ }^{*}$ For a given programming language with the optimizer enabled. A similar table is prepared with the optimizer disabled.

\section{Presentations}

During the last week of the semester, a one hour appointment is scheduled with each team so they can present their work accomplished during the semester. The presentations are open to faculty of our department, school, and the university. Students from other teams are not allowed to participate in each others team's final presentations.

The instructor and faculty ask the questions. Students are expected to "defend" their RFP or benchmark results according to the specifications and their assumptions. The presentations take place in a large electronic classroom equipped with PC's. Their PowerPoint images and results appear on a large 6' by 6' screen for viewing.

Prior to the final presentations, three or four checkpoints between student(s) and instructor are used for the teams to get feedback from the instructor regarding their progress. An ongoing iterative version of their progress in completing the project is placed in the team's project notebook.

\section{Project Notebook}

All teams are required to keep all their pertinent benchmark or RFP activities in a project notebook. Furthermore, they are required to submit their project notebook each time they give a presentation to the instructor. After each presentation, the project notebook is graded and returned to the team with appropriate suggestions for improvement. The teams are also expected to prepare a professional formal report and place it in their project notebook

The documentation in the formal report contains: 
(1) A cover page consisting of suitable information identifying the team and its members, course, institution and project.

(2) A table of contents

(3) An abstract of their project

(4) Gantt chart of the project and milestones accomplished

(5) A list of assumptions made pertaining to their project

(6) An introduction, including purpose, scope, etc

(7) The RFP that the company will issue or the benchmark performance timings achieved

(8) A description of any innovative/unique solutions

(9) Recommendations and conclusions regarding their project

(10) Bibliography of references

For the Benchmark Project, the following additional information is required and placed in appropriate appendices.

(11) A description of the computer system, compiler, interpreter, operating system, and other software used

(12) A copy of any algorithms used

(13) A general hierarchy chart of the project

(14) Instructions for operating the computer

(15) A list of any error/warning conditions (both system and program generated) concerning the project

(16) A description of any problems encountered such as portability, inconsistencies, hardware/software/people type problems, etc.

Students also place in their project notebook all directory listings, program listings, printer outputs, menus and screens of the displays, and the diskette or CD ROM containing all their benchmark programs or the RFP document.

\section{Feedback from CIS Alumni}

The students who are enrolled in this course are system networking, application programming, or systems analysis and design majors. They invariable ask, during the course, if they will ever use any of the topics, especially topics 5-13; i.e. preparation of RFP's, validation of vendor responses and system characteristics, performance measurements, selection techniques, vendor negotiations, procurement decision issues, and vendor contracts. Our reply is always an emphatic YES! However we caution the students that it will depend on where they work and in what capacity.

Furthermore, we inform the students that in their professional IT lifetime, they will be involved with performance measurements, RFPs etc., so they need to know as much about these topics as possible. Some of our more mature students, who have been working in the Information Technology field for many years have said, "I wish I had taken this course earlier."

Many of our CIS alumni who have entered the ranks of IT management, have told us how valuable the topics and experience gained in this course has been to their careers. Many of these alumni are engaged in the art of planning and procuring computer hardware, software, networks, IT services, and performance measurements. Graduates who have completed this course have 
made comments to include, "This course should be mandatory for all CIS graduates" and "I wish that I would have completed this course two years ago, when I was involved in preparing a major computer hardware and software acquisition for my company."

\section{Conclusions}

The following are some conclusions and recommendations to those faculty members thinking about teaching a course like this. Be prepared to spend extra time with your students. It's important that close supervision be maintained over the teams and the student's Benchmark or RFP Projects.

Also, be prepared to update the papers and articles on reserve in the library, as well as your lecture notes. Develop a Web site to keep and post current information for your students. Many new developments are occurring in the Information Technology field. This is a dynamic field where new computer hardware, software, and services appear daily. If possible, bring in guest speakers such as:

(1) A MIS/IT director, who can discuss the selection process from his organization's perspective.

(2) A vendor, who can discuss the selection process from a vendor's perspective.

(3) A Chief Financial Officer (CFO), who can discuss his organization's recent procurement decisions, how they were financed, and what role the RFP played.

(4) A lawyer, who can discuss the negotiation process, the important clauses necessary in computer-oriented contracts, and how to tie in the RFP and the vendor's proposal to their contract.

(5) A systems engineer, who can discuss common performance issues and the role of benchmarking.

In many ways, tomorrow's IT managers will be those who master their IT fundamentals in school, including how to develop effective RFP's and measure system performances. We endorse the concepts covered in this course for any CIS/IT curricula. This should be a senior level, capstone, course taken by CIS/IT majors so as to prepare them for the next level experience that they will encounter in industry..

\section{References}

Haag, S., Cummings, M., \& Dawkins, J. (1998). Management information systems for the information age. Boston, MA: Irwin McGraw-Hill.

Jessup, L. \& Valacich, J. (2002). Information systems today. Upper Saddle River, NJ: Prentice Hall

Lucas, H. C. (1971). Performance evaluation and monitoring. ACM Computing Surveys, 3 (2), 79-91.

Maniotes, J. \& Winer, C. R. (1999). Integration of field experiences in computer hardware/software selection: A senior capstone course. Proceedings of the $5^{\text {th }}$ World Multiconference on Systemics, Cybernetics, and Informatics (SCI), July 31-August 4; 8, 464-470.

Maniotes, J. \& Winer, C. R. (2003). Teaching the development of effective requests for proposals (RFP's) in the area of computer hardware/software/services selection. Proceedings of ISECON 2003, November 6-9, Paper 3113.

Maniotes, J., Winer, C. R., \& Maniotes, S. A. (2000). A computer performance course for an IS program. Proceedings of ISECON 2000, November 9-12, Paper 122. 
Maniotes, J., Winer, C. R., \& Maniotes, S. A. (2003). Computer hardware/software selection omnius. Hammond, IN: Purdue University Calumet.

Timmreck, E. M. (1973). Computer selection methodology. ACM Computing Surveys, 5 (4), 199-222.

Winer, C. R. \& Maniotes, J. (2001), The two and four year internet/web programs at Purdue University Calumet, Proceedings of ISECON 2001, November 1-4, Paper 18C.

\section{Biographies}

Dr. John Maniotes is Professor Emeritus, founder, and first Department Head in the Information Systems \& Computer Programming Department at Purdue University Calumet. He joined the faculty of the University in 1963, where he taught for 38 years. His professional experience includes over 45 years of information systems in the areas of: process control; simulation; computer hardware/software/services selection; RFP preparation, contract negotiations, and programming in a variety of computer languages. He earned his Ph.D., M.S., and B.S. degrees in Engineering from Purdue University. He has published 13 textbooks, 2 laboratory manuals, over 30 journal articles, and is the holder of one U.S. patent. He has also served as an I.T. consultant to many local school districts; town, city, and county governments; and to business and industry. In 2001, he received the Distinguished Service Award from the Purdue Calumet Alumni Association. He currently serves on the Board of Directors of Cenifax Management Services, a company specializing in computer consulting and facilities management.

Charles (Chuck) Winer is an Associate Professor and past Acting Department Head in the Information Systems \& Computer Programming Department at Purdue University Calumet. He joined the faculty of the University in 1983. His professional experience includes over thirty years of information systems consulting in the areas of: systems analysis and design, hardware and software evaluation (RFP \& contract considerations), and programming in Microsoft Access and Visual FoxPro, COBOL, Oracle database management system, Information Builders FOCUS/4GL/DBMS, and RPG/400. He holds the Certificate in Data Processing (CDP)/Certified Computing Professional (CCP) designations as awarded by the Institute for Certification of Computer Professionals (ICCP). In addition, he earned the M.A. and B.A. degrees in business education/information systems from Governors State University. Chuck has published several articles in industry journals, presented papers at national and international conferences. He was an invited keynote speaker at the $6^{\mathrm{TH}}$ World Multiconference on Systemics, Cybernetics and Informatics (SCI) \& Information Systems Analysis and Synthesis (ISAS) Conference 2000 in Orlando, Florida, and most recently was an invited speaker to the International Conference - Systemics, Cybernetics, and Informatics (ICSCI) 2004 in Hyderabad, India. He has been quoted in the PostTribune (Northwest Indiana newspaper), and has been a guest of the local public television station (WYIN) in Northwest Indiana. 